\title{
Managing Antidepressant Discontinuation: A Systematic Review
}

\author{
Emma Maund, MSc, MPbil, $P b D^{1}$ \\ Beth Stuart, MSc, $P b D^{1}$ \\ Michael Moore, BM BS, MRCP, \\ FRCGP ${ }^{1}$ \\ Christopher Dowrick, MSc, MD, \\ CQSW, FRCGP ${ }^{2}$ \\ Adam W.A. Geraghty, MSc, PbD, \\ CPsychol, FHEA ${ }^{1}$ \\ Sarab Dawson, MSc ${ }^{3}$ \\ Tony Kendrick, MD, FRCGP, FRC- \\ Psych (Hon), FHEA ${ }^{1}$ \\ 'Primary Care \& Population Sciences, Univer- \\ sity of Southampton, Aldermoor Health \\ Centre, Southampton, United Kingdom \\ ${ }^{2}$ Institute of Psychology Health and \\ Society, University of Liverpool, Liverpool, \\ United Kingdom \\ ${ }^{3}$ Department of Population Health \\ Sciences, Bristol Medical School, Univer- \\ sity of Bristol, Bristol, United Kingdom
}

Conflicts of interest: All authors but S.D. bave received funding from the National Institute for Health Research for the REDUCE (REviewing long term anti-DEpressant Use by Careful monitoring in Everyday practice) applied bealth research program 2016-2022 (bttp://www.isrctn. com/ISRCTN15036829). The authors declare no other financial relationships with any organizations that might have an interest in the submitted work in the previous 3 years, with the exception of S.D. who reports personal fees from University of York, University College London, and Maverex, outside the submitted work. The authors declare no other conflicts of interest.

\section{CORRESPONDING AUTHOR}

Tony Kendrick, MD, FRCGP, FRCPsych (Hon), FHEA

Primary Care \& Population Sciences,

University of Southampton

Aldermoor Health Centre

Southampton SO16 5ST, United Kingdom

A.R.Kendrick@soton.ac.uk

\begin{abstract}
PURPOSE We aimed to determine the effectiveness of interventions to manage antidepressant discontinuation, and the outcomes for patients.

METHODS We conducted a systematic review with narrative synthesis and meta-analysis of studies published to March 2017. Studies were eligible for inclusion if they were randomized controlled trials, quasi-experimental studies, or observational studies assessing interventions to facilitate discontinuation of antidepressants for depression in adults. Our primary outcomes were antidepressant discontinuation and discontinuation symptoms. Secondary outcomes were relapse/recurrence; quality of life; antidepressant reduction; and sexual, social, and occupational function.
\end{abstract}

RESULTS Of 15 included studies, 12 studies (8 randomized controlled trials, 2 single-arm trials, 2 retrospective cohort studies) were included in the synthesis. None were rated as having high risk for selection or detection bias. Two studies prompting primary care clinician discontinuation with antidepressant tapering guidance found $6 \%$ and $7 \%$ of patients discontinued, vs $8 \%$ for usual care. Six studies of psychological or psychiatric treatment plus tapering reported cessation rates of $40 \%$ to $95 \%$. Two studies reported a higher risk of discontinuation symptoms with abrupt termination. At 2 years, risk of relapse/recurrence was lower with cognitive behavioral therapy plus taper vs clinical management plus taper $(15 \%$ to $25 \%$ vs $35 \%$ to $80 \%$ : risk ratio $=0.34 ; 95 \% \mathrm{Cl}, 0.18-0.67 ; 2$ studies). Relapse/ recurrence rates were similar for mindfulness-based cognitive therapy with tapering and maintenance antidepressants ( $44 \%$ to $48 \%$ vs $47 \%$ to $60 \% ; 2$ studies).

CONCLUSIONS Cognitive behavioral therapy or mindfulness-based cognitive therapy can help patients discontinue antidepressants without increasing the risk of relapse/recurrence, but are resource intensive. More scalable interventions incorporating psychological support are needed.

Ann Fam Med 2019;17:52-60. https://doi.org/10.1370/afm.2336.

\section{INTRODUCTION}

I $\mathrm{n}$ Western countries, antidepressant prescriptions are rising steadily and have doubled over 10 years. ${ }^{1-3}$ The main reason is increasing longterm use ${ }_{1}^{4,5}$ with a median duration exceeding 5 years in the United States $^{2}$ and most prescribing done by primary care clinicians. ${ }^{2,5}$ Although some people need antidepressants to prevent relapse/recurrence, $30 \%$ to $50 \%$ of long-term users have no evidence-based indication to continue their medication. ${ }^{6-8}$ This inappropriate use exposes patients to potentially serious adverse effects ${ }^{9,10}$ and is costly. ${ }^{11}$

Stopping antidepressants, however, is frequently associated with withdrawal symptoms, which can be problematic, and mistaken for relapse/ recurrence. ${ }^{12}$ To minimize these symptoms, the American Psychiatric Association and the National Institute for Health and Care Excellence advise tapering doses over some weeks in most cases. ${ }^{13,14}$ Psychological interventions such as cognitive behavioral therapy (CBT) and mindfulnessbased cognitive therapy (MBCT) are potential alternatives to antidepressants for preventing relapse/recurrence. ${ }^{15-17}$ 
Current guidelines for antidepressant discontinuation are based on consensus, and nonsystematic reviews have identified a need for more controlled data. ${ }^{18}$ There have been 2 systematic reviews focusing on the incidence of withdrawal symptoms after discontinuation. ${ }^{12,19}$ We conducted a systematic review to address 2 questions: what interventions are effective in managing antidepressant discontinuation, and what are the outcomes for patients after discontinuation?

\section{METHODS}

Our protocol was registered with the International Prospective Register of Systematic Reviews (PROSPERO) in 2017, as reference CRD42017072702.

\section{Study Inclusion and Exclusion}

For our review, studies had to meet 4 main inclusion criteria. First, they had to take place among patients aged 18 years or older receiving antidepressants except monoamine oxidase inhibitors (MAOIs), which are usually prescribed by specialists, ${ }_{1}^{15}$ for treatment of a first or recurrent episode of depression (defined by study authors), regardless of duration of use or level of care (primary, secondary, tertiary) received. We included studies having patients with anxiety disorders if more than $50 \%$ of patients had depression, or if patients had mixed anxiety and depression. Second, studies had to assess interventions to facilitate discontinuation of antidepressants including guided review of patients by primary care clinicians, abrupt discontinuation, tapering, psychological therapies, and pharmacologic approaches (eg, switching to liquid fluoxetine during tapering). Third, studies with a comparator of continuation of antidepressant had to assess an alternative discontinuation procedure, usual care, or clinical management, but not placebo. Fourth, studies had to be randomized controlled trials (RCTs), cluster RCTs, quasi-experimental (nonrandomized studies, beforeand-after studies), or observational studies.

Studies were excluded if patients were allowed to have bipolar disorder or dementia, unless data were reported separately; if they concerned treatment interruption only; or if they were placebo-controlled trials aimed only at testing maintenance antidepressants in preventing relapse/recurrence.

\section{Outcomes}

Our primary outcomes were discontinuation of antidepressants, defined as cessation by the end of the study period, and discontinuation symptoms, either measured on the discontinuation emergent signs and symptoms (DESS) inventory or another scale, ${ }_{1}^{20}$ or listed. Our secondary outcomes were relapse/recurrence, as defined by study authors, either within 6 months, or more than 6 months after discontinuation; quality of life; antidepressant reduction; sexual function; other outcomes (eg, social and occupational function, well-being, quality of relationships).

We used the term relapse/recurrence to include both relapse, defined through consensus as the return of syndrome-level depression after remission during the first 4 to 6 months of treatment, and recurrence, defined as a new episode occurring after recovery and lasting more than 4 to 6 months. ${ }^{21}$ We used this approach because we did not specify a minimum duration of treatment before discontinuation, and patients included could have been in remission or recovery.

\section{Study Selection Process}

We searched the following databases from inception until March 2017: MEDLINE (Ovid), PubMed, Embase (Ovid), PsycINFO (EBSCOhost), AMED (EBSCOhost), Health Management Information Consortium (HMIC), OpenGrey, and the World Health Organization International Clinical Trials Registry Platform (WHO ICTRP). We searched citations and reference lists for full articles meeting inclusion criteria from initial searches, and contacted pharmaceutical companies and experts.

The MEDLINE search strategy was developed with an experienced health librarian (S.D.). It included subject headings and text words related to antidepressants, depression, discontinuation, and study design, and was peer reviewed by 3 medical librarians. This strategy was then adapted by E.M. for the remaining databases, except the WHO ICTRP, for which keyword combinations were used (Supplemental Appendix 1, available at http://www.AnnFamMed.org/ content/17/1/52/suppl/DC1/).

E.M. screened all titles and abstracts against inclusion criteria, and T.K. screened a $10 \%$ sample. We obtained full articles where titles or abstracts met the inclusion criteria, or where there was uncertainty. E.M. and T.K. independently assessed whether full articles met inclusion criteria. Disagreements were resolved by discussion.

Data extraction was performed in a standardized prepiloted form by E.M. and was thoroughly checked by T.K. It included patient and clinical characteristics (eg, age, sex, duration of antidepressant use); how withdrawal effects were ascertained; whether relapse/ recurrence was distinguished from withdrawal; and elements of the Template for Intervention and Replication (TIDieR) checklist. ${ }^{22}$ This information included physical/informational intervention materials, the party delivering the intervention (eg, primary care clinician, pharmacist, mental health practitioner), and how, where, and when it was delivered. 
Risk of bias assessment was performed by E.M. and checked by T.K. We used the Cochrane Risk of Bias tool, ${ }_{1}^{23}$ in accordance with the Cochrane Handbook for Systematic Reviews of Interventions. ${ }^{24}$ For observational studies and single-arm trials, we used tools provided by the National Heart, Lung, and Blood Institute and Research Triangle Institute International. ${ }^{25}$

Narrative and tabular summaries of key study characteristics, quality assessment, and results were undertaken. For each outcome, we present results by study design, separately for studies of patients with depression only and for patients with mixed depression and anxiety. Where appropriate, based on clinical and statistical heterogeneity, data were combined in meta-analyses. For binary outcomes we calculated risk ratios, and for continuous outcomes, we calculated mean differences, with $95 \%$ confidence intervals using a priori-specified random effects models. Statistical heterogeneity was tested using the $\chi^{2}$ test $(P<.1)$ and $\mathrm{I}^{2}$ statistic $\left(I^{2} \geq 50 \%\right)$.

We discussed the meaning of our results with 3 patient colleagues who provided patient and public input to our team.

\section{Figure 1. Flowchart of study selection.}

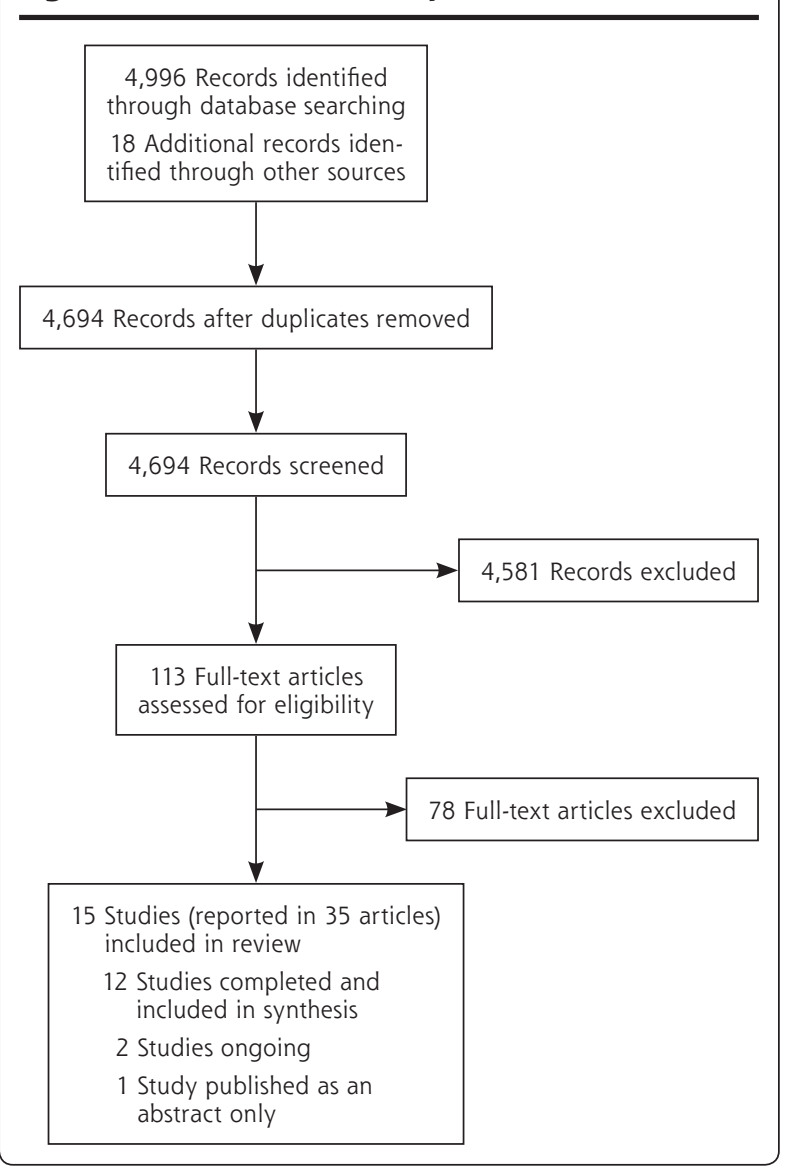

\section{RESULTS}

Our search yielded 4,996 records in total, 4,694 of which were unique (Figure 1). Of these records, 4,581 were ineligible after title and abstract review, with 99\% agreement in the $10 \%$ sample screened by T.K. Of the remaining 113 records, 78 records were excluded after assessment of full articles (see Supplemental Table 1, available at http://www.AnnFamMed.org/ content/17/1/52/suppl/DC1/ for excluded studies). Ultimately, 35 articles ${ }^{15-17,26-56}$ including 1 erratum, ${ }_{1}^{47}$ reporting 15 studies* were included. Of these 15 studies, 1 was published as an abstract only. ${ }^{26}$

Study characteristics are shown in Supplemental Table 2 (available at http://www.AnnFamMed.org/content/17/1/52/supp1/DC1/). Twelve studies were completed $^{\dagger}$ and included in our synthesis. Two, both RCTs, were ongoing: 1 of tapering for 2 weeks vs 1 week, ${ }^{56}$ and 1 of guided tapering plus CBT vs maintenance antidepressants in pregnant women. ${ }^{54,55}$

Eight of the completed studies were RCTs ${ }^{\ddagger}(1$ was a cluster $\mathrm{RCT}^{27}$ and 1 had only a single relevant study $\mathrm{arm}^{34}$ ), 2 were single-arm trials, ${ }_{,}^{49,50}$ and 2 were retrospective cohort studies. ${ }^{52,53}$ Study size ranged from 12 to 2,849 patients. ${ }^{49,50}$ Seven studies included participants with depression, anxiety disorder, or both, ${ }^{5}$ while 5 studies included only participants with depression. ${ }^{34,38,42,50,53}$ Criteria used for depression were reported in 9 studies: 7 studies used the Diagnostic and Statistical Manual 4th Edition (DSM-IV)" and 2 studies used the Research Diagnostic Criteria (RDC) 15,32 (Supplemental Table 2, available at http://www. AnnFamMed.org/content/17/1/52/suppl/DC1/).

Twelve studies named the antidepressants being discontinued: 2 studies reported discontinuation of single antidepressants (desvenlafaxine ${ }^{38}$ and paroxetine ${ }^{53}$ ), 1 study tricyclic antidepressants (TCAs) and related antidepressants, ${ }^{15} 1$ study newer antidepressants, ${ }^{50}$ 1 study predominantly selective serotonin reuptake inhibitors (SSRIs), ${ }^{42}$ and 7 studies both older and newer antidepressants.

Inclusion criteria for duration of use were reported in 8 studies: at least 4 weeks ( 1 study), ${ }^{50} 24$ weeks ( 1 study), ${ }^{38} 3$ to 5 months ( 1 study), ${ }_{1}^{15}$ at least 6 months ( 3 studies), ${ }_{1}^{16,34,42}$ at least 9 months ( 1 study), ${ }^{27}$ and at least 2 years ( 1 study). ${ }^{49}$ Three studies reported the mean or median length of antidepressant use, ${ }^{27,49,53}$ which ranged from 9.2 months ${ }^{53}$ to 9.5 years. ${ }^{27}$ Inclusion criteria for length of remission/recovery were reported

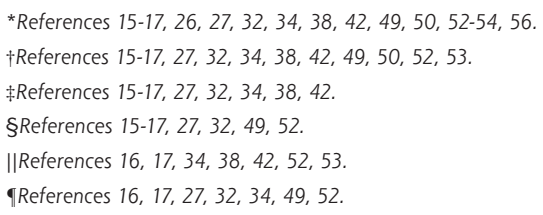


Table 1. Studies Reporting Discontinuation of Antidepressants

\begin{tabular}{|c|c|c|c|c|}
\hline Study, Year (Design) & Duration & $\begin{array}{l}\text { Intervention } \\
\text { (Cessation Rate) }\end{array}$ & $\begin{array}{l}\text { Comparator } \\
\text { (Cessation Rate) }\end{array}$ & $\begin{array}{l}\text { Risk Ratio } \\
(95 \% \mathrm{Cl})\end{array}$ \\
\hline \multicolumn{5}{|c|}{ Depression only (anxiety comorbidities were excluded or not reported) } \\
\hline Klein et $\mathrm{al}_{,}{ }^{42} 2017(\mathrm{RCT})^{\mathrm{a}}$ & 6 months & CBT + taper $(34 / 85=40 \%)$ & $\begin{array}{l}\text { Maintenance antidepressant } \\
\text { medication }(n / a)\end{array}$ & $\mathrm{n} / \mathrm{a}$ \\
\hline $\begin{array}{l}\text { Huijbers et al, }{ }^{34} 2016 \\
\quad\left(\text { Single arm from RCT) }{ }^{b}\right.\end{array}$ & $\begin{array}{l}6 \text { months; after } \\
6 \text { months }\end{array}$ & $\begin{array}{l}\text { MBCT-TS }(68 / 128=53 \% \\
70 / 128=55 \%)\end{array}$ & $\mathrm{n} / \mathrm{a}$ & $\mathrm{n} / \mathrm{a}$ \\
\hline \multicolumn{5}{|c|}{ Depression andlor anxiety disorders } \\
\hline Eveleigh, 272015 (RCT) & 12 months & $\begin{array}{l}\text { Letter to primary care clinician } \\
\text { with recommendation + tapering } \\
\text { advice }(4 / 67=6 \%)\end{array}$ & Usual care $(6 / 75=8 \%)$ & $\begin{array}{l}0.75(0.22-2.53) \\
1 \text { study }\end{array}$ \\
\hline Fava et al, ${ }^{15} 1994$ (RCT) & 20 weeks & CBT $+\operatorname{taper}(20 / 21=95 \%)$ & $\begin{array}{l}\text { Clinical management }+ \text { taper } \\
\quad(20 / 22=91 \%)\end{array}$ & $\begin{array}{l}1.01(0.89-1.15 ; \\
\left.I^{2}=0 \%\right) ; 2 \text { studies }\end{array}$ \\
\hline Fava et al,32 1998 (RCT) & 20 weeks & CBT + taper $(20 / 23=87 \%)$ & $\begin{array}{l}\text { Clinical management }+ \text { taper } \\
\quad(20 / 22=91 \%)\end{array}$ & \\
\hline Kuyken et al, ${ }^{17} 2015(\mathrm{RCT})^{\mathrm{d}}$ & 24 months & MBCT-TS $(124 / 176=70 \%)$ & $\begin{array}{l}\text { Maintenance antidepressant } \\
\text { medication (n/a) }\end{array}$ & $\mathrm{n} / \mathrm{a}$ \\
\hline $\begin{array}{l}\text { Johnson et al, }{ }^{49} 2012 \\
\text { (single-arm trial) }\end{array}$ & Postintervention & $\begin{array}{l}\text { Guided primary care clinician } \\
\text { review }(199 / 2,849=7 \%)\end{array}$ & $\mathrm{n} / \mathrm{a}$ & $\mathrm{n} / \mathrm{a}$ \\
\hline \multicolumn{5}{|c|}{$\begin{array}{l}\mathrm{CBT}=\text { cognitive behavioral therapy; ITT = intention to treat; } \mathrm{MBCT}=\text { mindfulness-based cognitive therapy; } \mathrm{MBCT} \text {-TS = mindfulness-based cognitive therapy with sup- } \\
\text { port to taper; } \mathrm{n} / \mathrm{a}=\text { not applicable; } \mathrm{RCT}=\text { randomized controlled trial. }\end{array}$} \\
\hline \multicolumn{5}{|c|}{ a A 3-arm RCT, but only 2 arms were relevant for this review; ITT analysis. } \\
\hline \multicolumn{5}{|c|}{$\begin{array}{l}{ }^{b} \text { A 2-arm RCT, but only } 1 \text { arm was relevant for this review (second arm: MBCT + maintenance antidepressant medication); ITT analysis. } \\
\text { c ITT analysis. }\end{array}$} \\
\hline
\end{tabular}

in 4 studies, ${ }^{32,34,42,50}$ with a range from 8 weeks $^{42}$ to 6 months. ${ }^{50}$ Three studies of MBCT included a sizable proportion of patients in partial remission ${ }^{16,17,34}$ (Supplemental Table 2, available at http://www. AnnFamMed.org/content/17/1/52/suppl/DC1/).

Interventions were varied: patient-specific letters to the primary care clinician with a recommendation to discontinue antidepressant and tapering advice ${ }^{27}$; prompted primary care clinician review of the condition and the meication ${ }^{49}{ }_{i}$ CBT with tapering ${ }^{15,32,42,50}$; MBCT with tapering ${ }^{16,17,34}$; gradual discontinuation $^{52,53}$; and 1 week of tapering. ${ }^{38}$ Comparators were similarly varied: maintenance antidepressant treatment, rapid discontinuation; abrupt discontinuation; clinical management plus taper; and usual care (Supplemental Table 2, available at http://www. AnnFamMed.org/content/17/1/52/suppl/DC1/). Apart from sexual function, data were reported for all of our prespecified outcomes of interest.

None of the included randomized controlled trials was rated as having high risk for selection or detection bias. Performance bias was rated as either high risk because of the nature of interventions or unclear (Supplemental Table 3, available at http://www. AnnFamMed.org/content/17/1/52/suppl/DC1/). Singlearm trials had clearly defined, valid, reliable, and consistently implemented outcome measures, and for both types of observational studies, time frames were suf- ficient to see associations between exposure and outcomes (Supplemental Table 4, available at http://www. AnnFamMed.org/content/17/1/52/suppl/DC1/).

\section{Discontinuation of Antidepressants}

Eight studies (6 randomized controlled trials and 2 single-arm trials) reported on discontinuation (Table 1). . Time points ranged from end of intervention to 24 months from baseline, and cessation rates ranged from $6 \%$ to $95 \%$. The lowest rate was seen with patient-specific letters to primary care clinicians recommending antidepressant discontinuation, with tapering advice. ${ }^{27}$ There was no significant difference in cessation between this approach $(6 \%)$ and usual care $(8 \%)$ after 12 months (risk ratio $[\mathrm{RR}]=0.75 ; 95 \% \mathrm{CI}$, $0.22-2.53)$. Patients who discontinued tended to have a shorter duration of use.

The highest cessation rates ( $87 \%$ and $95 \%)$ were seen in 2 studies comparing CBT plus tapering with clinical management plus tapering, delivered by the same psychiatrist. ${ }^{15,32}$ When results from these studies were combined in meta-analysis, there was no significant difference in discontinuation after 20 weeks $\left(\mathrm{RR}=1.01 ; 95 \% \mathrm{CI}, 0.89-1.15 ; \chi^{2}=0.49, \mathrm{I}^{2}=0 \%\right)$. Cessation rates in 3 studies of MBCT with tapering support ranged from $55 \%$ to $75 \%$. $^{16,17,34}$

"References 15-17, 27, 32, 34, 42, 49. 
Table 2. Studies Reporting Antidepressant Discontinuation Symptoms

\begin{tabular}{|c|c|c|c|c|c|}
\hline $\begin{array}{l}\text { Study, Year } \\
\text { (Design) }\end{array}$ & Duration & Outcome & $\begin{array}{l}\text { Intervention } \\
\text { (Symptom Rate) }\end{array}$ & $\begin{array}{l}\text { Comparator } \\
\text { (Symptom Rate) }\end{array}$ & $\begin{array}{l}\text { Risk Ratio } \\
(95 \% \mathrm{Cl})\end{array}$ \\
\hline \multirow[t]{2}{*}{$\begin{array}{l}\text { Khan et al, }{ }^{38} 2014 \\
\quad(R C T)\end{array}$} & \multirow[t]{2}{*}{4 weeks } & $\begin{array}{l}\text { Incidence of taper-/posttherapy- } \\
\text { emergent adverse events }\end{array}$ & $\begin{array}{l}\text { 1-week taper } \\
\qquad(54 / 139=39 \%)\end{array}$ & $\begin{array}{l}\text { Abrupt discontinua- } \\
\text { tion }(75 / 146=51 \%)\end{array}$ & $\begin{array}{l}0.76(0.58-0.98) ; \\
1 \text { study }\end{array}$ \\
\hline & & $\begin{array}{l}\text { Proportion of patients with } \\
\text { discontinuation syndrome }\end{array}$ & $\begin{array}{l}\text { 1-week taper } \\
\qquad(30 / 139=22 \%)\end{array}$ & $\begin{array}{l}\text { Abrupt discontinua- } \\
\quad \text { tion }(31 / 146=21 \%)\end{array}$ & $\begin{array}{l}1.02(0.65-1.59) \\
1 \text { study }\end{array}$ \\
\hline $\begin{array}{l}\text { Himei and Okamura, }{ }^{53} \\
2006 \text { (retrospective } \\
\text { cohort study) }\end{array}$ & 8 weeks & $\begin{array}{l}\text { Incidence of discontinuation } \\
\text { syndrome }\end{array}$ & $\begin{array}{l}\text { Gradual withdrawal } \\
\qquad(14 / 305=5 \%)\end{array}$ & $\begin{array}{l}\text { Abrupt withdrawal } \\
(27 / 80=34 \%)\end{array}$ & $\begin{array}{l}0.14(0.07-0.25) \\
1 \text { study }\end{array}$ \\
\hline
\end{tabular}

DESS = discontinuation emergent signs and symptoms; RCT = randomized controlled trial; SSRI = selective serotonin reuptake inhibitor.

Note: All studies took place among patients with depression only (anxiety comorbidities were excluded or not reported).

a Adverse events that started or increased in severity during the double blind phase.

${ }^{b}$ An increase of 4 or more points in DESS between baseline and mean score during the first 2 weeks of the double-blind phase.

${ }^{c}$ Diagnosis in medical records and reconfirmation of diagnosis according to criteria for SSRI discontinuation syndrome proposed by Black et al ${ }^{57}$ : (1) symptoms of discontinuation syndrome appear within 3 days following cessation/reduction in the dosage of paroxetine; (2) 2 or more of the following symptoms are present: dizziness, light-headedness, headache, nausea, paraesthesia, loss of balance, irritability, agitation, and insomnia; (3) symptoms cannot be explained as a relapse of depression or as any other medical condition; and (4) symptoms cause significant distress or impairment in social, occupational, and other important areas of functioning.

${ }^{\mathrm{d}} \mathrm{A} 10$-mg reduction every 2 weeks.

\section{Discontinuation Symptoms}

One RCT and 1 retrospective cohort study reported on discontinuation symptoms (Table 2). ${ }^{38,53}$ The RCT compared abrupt discontinuation of desvenlafaxine $50 \mathrm{mg} /$ day vs tapering using $25 \mathrm{mg} /$ day for 1 week. $^{38}$ There was significantly lower risk of discontinuation-emergent adverse events with the 1 -week taper $(\mathrm{RR}=0.76 ; 95 \%$ CI, 0.58-0.98) but no statistically significant difference in the risk of discontinuation syndrome. The study may have been underpowered to detect a difference, however, with 140 patients in the tapering arm and 148 patients in the abrupt discontinuation arm.

The retrospective cohort study assessed outcomes among 385 patients treated with paroxetine for a single episode of major depressive disorder. ${ }^{53}$ Discontinuation syndrome occurred significantly less frequently in patients who discontinued gradually, with a $10-\mathrm{mg}$ reduction every 2 weeks, compared with patients who discontinued abruptly $(5 \%$ vs $34 \%$; $\mathrm{RR}=0.14 ; 95 \% \mathrm{CI}$, 0.07-0.25). Patients experiencing discontinuation syndrome were significantly younger $(P=.02)$, but more young patients discontinued abruptly. Of 41 patients experiencing discontinuation syndrome, 36 were restarted on paroxetine and subsequently tapered off at 5 mg every 2 to 4 weeks, with no recurrence of discontinuation syndrome. As 10-mg tablets were the only form available, however, patients had to split them.

\section{Relapse/Recurrence Within 6 Months}

Three studies (1 single-arm trial and 2 retrospective cohort studies) reported relapse/recurrence within 6 months of discontinuation (Supplemental Table 5, available at http://www.AnnFamMed.org/content/17/1/52/suppl/DC1/)..$^{50,52,53}$ In both cohort studies, investigators attempted to differentiate discontinua- tion symptoms from relapse/recurrence: for example, 1 study's inclusion criteria stated that patients had to remain euthymic for 1 week after discontinuation. ${ }^{52}$

One small feasibility study of CBT for preventing recurrence in 12 women who wished to discontinue before pregnancy found that 2 women had a recurrence within 10 weeks of tapering. ${ }^{50}$ In a retrospective cohort study, of 41 patients who experienced discontinuation syndrome after stopping paroxetine, none had a recurrence after a subsequent slower titration $(88 \%)$ or switch of antidepressants (12\%). ${ }^{53}$ In a second cohort study, median time to recurrence of depressive or panic disorder was more than twice as long after gradual vs rapid discontinuation. ${ }^{52}$ Newer antidepressants (SSRIs, bupropion, duloxetine, venlafaxine) were associated with a shorter time to recurrence than TCA or tetracyclic antidepressants. ${ }^{52}$

\section{Recurrence After More Than 6 Months}

Six studies reported on late recurrence (Supplemental Table 6, available at http://www.AnnFamMed.org/content/17/1/52/suppl/DC1/) at time points ranging from 12 months to 6 years after discontinuation. ${ }^{15-17,27,32,34}$ One study used as its definition a score of 5 on the Structured Clinical Interview for Depression Longitudinal Interval Follow-up Evaluation (SCID-LIFE) for 2 weeks, which could have included patients experiencing withdrawal affecting mood temporarily and led to overestimation of recurrence. ${ }^{18}$

There was no significant difference in recurrence after patient-specific recommendations to primary care clinicians to discontinue plus tapering guidance, compared with usual care (26\% vs $13 \%$ : RR $=1.95$; 95\% CI, 0.97-3.94). ${ }^{27}$ Meta-analysis of 2 studies ${ }^{15,32}$ showed significantly lower risks of recurrence with 
CBT plus taper compared with clinical management plus taper after 2 years ( $15 \%$ to $25 \%$ vs $35 \%$ to $80 \%$ : $\left.\mathrm{RR}=0.34 ; 95 \% \mathrm{CI}, 0.18-0.67 ; \chi^{2}=0.19, \mathrm{I}^{2}=0 \%\right)$ and after 6 years $(40 \%$ to $50 \%$ vs $75 \%$ to $90 \%$ : RR $=0.55$; $\left.95 \% \mathrm{CI}, 0.37-0.82 ; \chi^{2}=1.12, \mathrm{I}^{2}=11 \%\right)$. Meta-analysis of 2 studies ${ }^{16,17}$ showed no difference in recurrence between MBCT with tapering support vs maintenance antidepressants at 15 months or more $(44 \%$ to $48 \%$ vs $47 \%$ to $60 \%: \mathrm{RR}=0.90 ; 95 \% \mathrm{CI}, 0.75-1.07 ; \chi^{2}=0.68$, $\left.\mathrm{I}^{2}=0 \%\right)$. The recurrence rate at 15 months was similar $(54 \%)$ in another study providing MBCT with tapering support in $1 \mathrm{arm} .{ }^{34}$

\section{Quality of Life}

Four studies (3 RCTs and 1 single-arm trial) reported on quality of life (Supplemental Table 7, available at http://www.AnnFamMed.org/content/17/1/52/suppl/ DC1/). ${ }^{16,17,27,50}$ One study using letters to primary care clinician with a recommendation to discontinue antidepressant and tapering advice found no significant effect on quality-adjusted life-years. ${ }^{27}$

Meta-analysis was possible for 2 studies comparing MBCT with tapering vs maintenance antidepressants. ${ }^{16,17}$ Results showed no significant difference on the physical domain of a World Health Organization Quality of Life instrument (the WHOQOL-BREF), but a statistically significant difference favoring MBCT with tapering support in the psychological and social domains after 1 month. At 12 months and longer, there was no statistically significant difference for any of the 3 domains.

One study found no statistically significant difference in scores on the European Quality of Life 5 dimensions questionnaire (EQ-5D) between MBCT with tapering support and maintenance antidepressants at any assessed time points. ${ }^{17}$ In a small single-arm CBT study, quality of life scores for participants who did not experience relapse (9 out of 12) decreased after 16 weeks of acute treatment but improved again at 24 weeks after booster treatment. ${ }^{50}$

\section{Reduction in Antidepressant Use}

Four studies reported on reductions in antidepressant use (Supplemental Table 8, available at http://www. AnnFamMed.org/content/17/1/52/suppl/DC1/). 17,34,42,49 The percentage of patients reducing their antidepressant use ranged from $13 \%$ with primary care clinician review to $19 \%$ achieving at least a $50 \%$ reduction with CBT plus tapering. ${ }^{42,49}$

\section{DISCUSSION}

\section{Summary of Main Findings}

We found discontinuation rates varied from only $6 \%$ to $7 \%$ for prompted primary care clinician patient review and guided tapering, to $40 \%$ to $95 \%$ for specialist psychological or psychiatric interventions. Merely 2 studies reported on discontinuation symptoms. One $\mathrm{RCT}^{38}$ found a lower risk of serious adverse events with 1-week taper vs abrupt discontinuation of desvenlafaxine, whereas a retrospective cohort study ${ }^{53}$ found discontinuation syndrome significantly more common after abrupt paroxetine cessation.

Rates of relapse/recurrence were low in primary care (13\% to $26 \%)$ compared with psychiatric or psychological therapy settings (15\% to $90 \%)$, presumably related to the larger proportion of patients with multiple recurrences, partial remissions on antidepressants, or both in specialist settings, but there has been very little research in primary care. A primary care placebocontrolled trial of maintenance SSRI treatment to prevent depression recurrence (excluded from this review) found similar recurrence rates: $10 \%$ in the continuation arm and $23 \%$ in the taper arm over 18 months. ${ }^{58}$

The risk of relapse/recurrence was significantly reduced with the combination of CBT and tapering vs clinical management and tapering alone. MBCT with tapering enabled high rates of discontinuation without increasing relapse/recurrence rates, as compared with maintenance antidepressants.

\section{Strengths and Limitations}

We conducted a sensitive search across several databases, including gray literature, unrestricted by date, language, or publication status, to minimize publication and language bias. One researcher performed study selection, data extraction, and risk of bias assessment, with extracted data and bias assessments carefully checked by another experienced reviewer. This approach is time-efficient but may incur more errors than full data extraction by 2 reviewers. ${ }^{59}$

\section{Comparison With the Literature}

Our findings tend to support consensus guidance that antidepressants should be tapered rather than discontinued abruptly, but more trials of slower tapering are needed. ${ }^{18}$ One ongoing study is comparing 1 -week with 2-week tapering. ${ }^{56}$ Our findings are consistent with those of short-term drug interruption studies (also excluded from this review) showing that discontinuation syndrome occurs more often on abrupt cessation of paroxetine, presumably because of its short half-life. ${ }^{60,61}$

Discontinuation took place in some studies during "continuation" treatment to prevent relapse within 4 to 6 months of remission, and in others during "maintenance" treatment to prevent recurrence. ${ }^{62}$ This distinction is potentially important, because guidelines recommend 6 to 9 months of continuation treatment 
for a first episode of depression, and maintenance treatment for 2 years or longer for recurrent episodes. ${ }^{13,14}$ The clinical utility of this distinction has however been questioned by a systematic review that found no clear difference between continuation and maintenance treatment in reducing the risk of relapse/recurrence. ${ }^{63}$

\section{Implications for Practice and Research}

It is important for primary care clinicians to discuss discontinuation symptoms with patients at the time of initiation of an antidepressant. Doing so will allow patients to make more informed decisions about whether they want to start an antidepressant in the first place. Patients may also be reassured that relapse rates may be lower in the primary care setting, although more research needs to be done to confirm that.

Discontinuation symptoms are probably reduced by tapering, but slow tapering is a challenge given a lack of suitable formulations. One study found that most patients could discontinue paroxetine with a taper of $5 \mathrm{mg}$ every 2 to 4 weeks, but patients had to break tablets in half. ${ }^{53}$ Switching to fluoxetine, with its longer half-life and availability in liquid form, may enable successful slow tapering, ${ }_{1}^{18}$ but this strategy does not appear to have been tested in a trial.

Discontinuation symptoms may affect patients' willingness to stop antidepressants and be confounded with relapse/recurrence, so future studies should distinguish between these events. They should also distinguish between discontinuing continuation vs maintenance antidepressant treatment.

Providing psychological therapies seems to enable significantly higher discontinuation rates as compared with brief guidance on tapering to primary care clinicians alone. This approach may work by providing support to patients to manage fears of withdrawal, relapse, and lack of self-efficacy, which are possible barriers to discontinuation. ${ }^{64}$ Alternately, having an effective therapy for the depression or anxiety for which the medication was initially given removes the need for it, without increasing relapse/recurrence risk. Access to face-to-face CBT or MBCT is likely to be quite limited, however. This situation warrants exploration of psychologically informed digital support for discontinuation to complement primary care clinician management, given the high prevalence of people on potentially inappropriate long-term antidepressant treatment.

To read or post commentaries in response to this article, see it online at http://www.AnnFamMed.org/content/17/1/52.

Key words: mental health; depression; antidepressants; discontinuation syndrome; primary care; prescribing; deprescribing

Submitted June 14, 2018; submitted, revised, October 8, 2018; accepted November 1, 2018.
Funding support: This article reports independent research funded by the National Institute for Health Research (Programme Grants for Applied Research, REviewing long-term anti-Depressant Use by Careful monitoring in Everyday practice [REDUCE] programme-Ref RP-PG-1214-20004).

Disclaimer: The views expressed in this publication are those of the authors and not necessarily those of the NHS, the National Institute for Health Research, or the Department of Health.

Previous presentations: The main conclusions were presented by A.W.A.G. at the Society for Academic Primary Care Annual Scientific Meeting; July 11, 2018; London, United Kingdom; as part of a 10-minute oral presentation "REDUCE program to help people withdraw from inappropriate long-term antidepressant treatment." They were also presented by T.K. at the National Institute for Health Research School for Primary Care Research showcase conference; November 13, 2018; London, United Kingdom; as part of a 15-minute plenary presentation "REviewing long term anti-Depressant Use by Careful monitoring in Everyday practice (REDUCE) programme".

Supplementary materials: Available at http://www.AnnFamMed. org/content/17/1/52/suppl/DC1/.

\section{References}

1. McCarthy M. Antidepressant use has doubled in rich nations in past 10 years. BMJ. 2013;347:f7261.

2. Pratt L, Brody D, Gu Q. Antidepressant use in persons aged 12 and over: United States, 2005-2008. NCHS data brief no. 76. Hyattsville, MD: National Center for Health Statistics; 2011. https:// www.cdc.gov/nchs/data/databriefs/db76.pdf. Published Oct 2011. Accessed Jun 2018.

3. Mojtabai R, Olfson M. National trends in long-term use of antidepressant medications: results from the U.S. National Health and Nutrition Examination Survey. J Clin Psychiatry. 2014;75(2):169-177.

4. Moore M, Yuen HM, Dunn N, Mullee MA, Maskell J, Kendrick T. Explaining the rise in antidepressant prescribing: a descriptive study using the general practice research database. BMJ. 2009;339:b3999.

5. Kendrick T, Stuart B, Newell C, Geraghty AWA, Moore M. Did NICE guidelines and the Quality Outcomes Framework change GP antidepressant prescribing in England? Observational study with time trend analyses 2003-2013. J Affect Disord. 2015;186:171-177.

6. Cruickshank G, Macgillivray S, Bruce D, Mather A, Matthews K, Williams B. Cross-sectional survey of patients in receipt of long-term repeat prescriptions for antidepressant drugs in primary care. Ment Health Fam Med. 2008;5(2):105-109.

7. Ambresin G, Palmer V, Densley K, Dowrick C, Gilchrist G, Gunn JM. What factors influence long-term antidepressant use in primary care? Findings from the Australian diamond cohort study. J Affect Disord. 2015;176:125-132.

8. Piek E, Kollen BJ, van der Meer K, Penninx BWJH, Nolen WA. Maintenance use of antidepressants in Dutch general practice: nonguideline concordant. PLoS One. 2014;9(5):e97463.

9. Ferguson JM. SSRI antidepressant medications: adverse effects and tolerability. Prim Care Companion J Clin Psychiatry. 2001;3(1):22-27.

10. Coupland C, Dhiman P, Morriss R, Arthur A, Barton G, HippisleyCox J. Antidepressant use and risk of adverse outcomes in older people: population based cohort study. BMJ. 2011;343:d4551.

11. Vasiliadis HM, Latimer E, Dionne PA, Préville M. The costs associated with antidepressant use in depression and anxiety in community-living older adults. Can J Psychiatry. 2013;58(4):201-209.

12. Fava GA, Gatti A, Belaise C, Guidi J, Offidani E. Withdrawal symptoms after selective serotonin reuptake inhibitor discontinuation: a systematic review. Psychother Psychosom. 2015;84(2):72-81. 
13. American Psychiatric Association. Practice Guideline for the Treatment of Patients With Major Depressive Disorder. 3rd ed. https://psychiatry online.org/pb/assets/raw/sitewide/practice_guidelines/guidelines/ mdd.pdf. Accessed Jun 2018.

14. National Collaborating Centre for Mental Health. Depression: The NICE Guideline on the Treatment and Management of Depression in Adults (updated edition); National Clinical Practice Guideline 90. https:// www.ncbi.nlm.nih.gov/books/NBK63748/. Published 2010. Accessed Jun 2018.

15. Fava GA, Grandi S, Zielezny M, Canestrari R, Morphy MA. Cognitive behavioral treatment of residual symptoms in primary major depressive disorder. Am J Psychiatry. 1994;151(9):1295-1299.

16. Kuyken W, Byford S, Taylor RS, et al. Mindfulness-based cognitive therapy to prevent relapse in recurrent depression. J Consult Clin Psychol. 2008;76(6):966-978.

17. Kuyken W, Hayes R, Barrett $B$, et al. The effectiveness and costeffectiveness of mindfulness-based cognitive therapy compared with maintenance antidepressant treatment in the prevention of depressive relapse/recurrence: results of a randomised controlled trial (the PREVENT study). Health Technol Assess. 2015;19(73):1-124.

18. Wilson $E$, Lader M. A review of the management of antidepressant discontinuation symptoms. Ther Adv Psychopharmacol. 2015;5(6): 357-368.

19. Davies J, Read J. A systematic review into the incidence, severity and duration of antidepressant withdrawal effects: are guidelines evidence-based? [published online ahead of print October 5, 2018]. Addict Behav. https://doi.org/10.1016/j.addbeh.2018.08.027.

20. Rosenbaum JF, Fava M, Hoog SL, Ascroft RC, Krebs W/B. Selective serotonin reuptake inhibitor discontinuation syndrome: a randomized clinical trial. Biol Psychiatry. 1998;44(2):77-87.

21. Frank E, Prien RF, Jarrett RB, et al. Conceptualization and rationale for consensus definitions of terms in major depressive disorder. Remission, recovery, relapse, and recurrence. Arch Gen Psychiatry. 1991;48(9):851-855.

22. Hoffmann T, Glasziou P, Boutron I, et al. Better reporting of interventions: template for intervention description and replication (TIDieR) checklist and guide. BMJ. 2014;348:g1687.

23. Higgins JP, Altman DG, Gøtzsche PC, et al; Cochrane Bias Methods Group; Cochrane Statistical Methods Group. The Cochrane Collaboration's tool for assessing risk of bias in randomised trials. BMJ. 2011;343:d5928.

24. Higgins J, Green S, eds. Cochrane Handbook for Systematic Reviews of Interventions Version 5.1.0. London, United Kingdom: The Cochrane Collaboration; 2011. https://handbook-5-1.cochrane.org/. Updated Mar 2011. Accessed Jun 2018.

25. National Heart, Lung, and Blood Institute, Research Triangle Institute International. Study Quality Assessment Tools. Bethesda, Maryland: National Heart Lung and Blood Institute. https://www.nlhbi. nih.gov/health-topics/study-quality-assessment-tools. Published 2014. Accessed Jun 2018.

26. Dan IA, Simu M. The "discontinuation syndrome" in depressed patients successfully treated with sertraline. Eur Neuropsychopharmacol. 2000;10 (Suppl 3):S273-S274. Abstract no. 136.

27. Eveleigh R. Inappropriate Long-Term Antidepressant Use in Primary Care: A Challenge to Change [PhD thesis]. Njimegen, The Netherlands: Radboud University Njimegen; 2015.

28. Muskens $E$, Eveleigh R, Lucassen $P$, et al. Prescribing ANtiDepressants Appropriately (PANDA): a cluster randomized controlled trial in primary care. BMC Fam Pract. 2013;14:6.

29. Eveleigh R, Grutters J, Muskens E, et al. Cost-utility analysis of a treatment advice to discontinue inappropriate long-term antidepressant use in primary care. Fam Pract. 2014;31(5):578-584.

30. Fava GA, Grandi S, Zielezny M, Rafanelli C, Canestrari R. Four-year outcome for cognitive behavioral treatment of residual symptoms in major depression. Am J Psychiatry. 1996;153(7)(suppl):945-947.
31. Fava GA, Rafanelli C, Grandi S, Canestrari R, Morphy MA. Six-year outcome for cognitive behavioral treatment of residual symptoms in major depression. Am J Psychiatry. 1998;155(10):1443-1445.

32. Fava GA, Rafanelli C, Grandi S, Conti S, Belluardo P. Prevention of recurrent depression with cognitive behavioral therapy: preliminary findings. Arch Gen Psychiatry. 1998;55(9):816-820.

33. Fava GA, Ruini C, Rafanelli C, Finos L, Conti S, Grandi S. Six-year outcome of cognitive behavior therapy for prevention of recurrent depression. Am J Psychiatry. 2004;161(10):1872-1876.

34. Huijbers MJ, Spinhoven P, Spijker J, et al. Discontinuation of antidepressant medication after mindfulness-based cognitive therapy for recurrent depression: randomised controlled non-inferiority trial. $\mathrm{Br}$ J Psychiatry. 2016;208(4):366-373.

35. Huijbers MJ, Spijker J, Donders ART, et al. Preventing relapse in recurrent depression using mindfulness-based cognitive therapy, antidepressant medication or the combination: Trial design and protocol of the MOMENT study. BMC Psychiatry. 2012;12:125.

36. Huijbers MJ, Spinhoven P, van Schaik DJF, Nolen WA, Speckens AEM. Patients with a preference for medication do equally well in mindfulness-based cognitive therapy for recurrent depression as those preferring mindfulness. J Affect Disord. 2016;195:32-39.

37. ClinicalTrials.gov. Mindfulness based cognitive therapy and antidepressant medication in recurrent depression. https://clinicaltrials. gov/ct2/show/NCT00928980. Published Jun 26, 2009. Updated Nov 8, 2013. Accessed Aug 2, 2018.

38. Khan A, Musgnung J, Ramey T, Messig M, Buckley G, Ninan PT. Abrupt discontinuation compared with a 1-week taper regimen in depressed outpatients treated for 24 weeks with desvenlafaxine 50 mg/d. J Clin Psychopharmacol. 2014;34(3):365-368.

39. Ninan PT, Musgnung J, Messig M, Buckley G, Guico-Pabia CJ، Ramey TS. Incidence and timing of taper/posttherapy-emergent adverse events following discontinuation of desvenlafaxine $50 \mathrm{mg} / \mathrm{d}$ in patients with major depressive disorder. Prim Care Companion CNS Disord. 2015;17(1).

40. ClinicalTrials.gov. Study comparing discontinuation symptoms of DVS SR in subjects with major depressive disorder (MDD). https:// clinicaltrials.gov/ct2/show/NCT01056289. Published Jan 26, 2010. Updated Feb 28, 2012. Accessed Aug 2, 2018.

41. ISRCTN Registry. Trial platform: preventing depression relapse in the National Health Service practice using mindfulness-based cognitive therapy. https://doi.org/10.1186/ISRCTN12720810. Updated Jul 31, 2012. Accessed Aug 2, 2018.

42. Klein NS, van Rijsbergen GD, Ten Doesschate MC, Hollon SD, Burger $\mathrm{H}$, Bockting CLH. Beliefs about the causes of depression and recovery and their impact on adherence, dosage, and successful tapering of antidepressants. Depress Anxiety. 2017;34(3):227-235.

43. Bockting CLH, Elgersma HJ, van Rijsbergen GD, et al. Disrupting the rhythm of depression: Design and protocol of a randomized controlled trial on preventing relapse using brief cognitive therapy with or without antidepressants. BMC Psychiatry. 2011;11:8.

44. ISRCTN Registry. Imagine your mood: a step towards personalized relapse prevention in depression. https://doi.org/10.1186/ ISRCTN15472145. Updated Nov 8, 2017. Accessed Aug 2, 2018.

45. Kuyken W, Byford S, Byng R, et al. Study protocol for a randomized controlled trial comparing mindfulness-based cognitive therapy with maintenance anti-depressant treatment in the prevention of depressive relapse/recurrence: The PREVENT trial. Trials. 2010;11:99.

46. Kuyken W, Byford S, Byng R, et al. Update to the study protocol for a randomized controlled trial comparing mindfulness-based cognitive therapy with maintenance anti-depressant treatment depressive relapse/recurrence: The PREVENT trial. Trials. 2014;15(1):217.

47. Kuyken W, Hayes R, Barrett B, et al. Effectiveness and costeffectiveness of mindfulness-based cognitive therapy compared with maintenance antidepressant treatment in the prevention 
of depressive relapse or recurrence (PREVENT): a randomised controlled trial [published correction appears in Lancet. 2016; 388(10052):1376]. Lancet. 2015;386(9988):63-73.

48. ISRCTN Registry. Preventing depressive relapse/recurrence in NHS settings through mindfulness based cognitive therapy (MBCT). https://doi.org/10.1186/ISRCTN26666654. Updated Sep 18, 2015. Accessed Aug 2, 2018.

49. Johnson CF, Macdonald HJ, Atkinson P, Buchanan Al, Downes $N$, Dougall N. Reviewing long-term antidepressants can reduce drug burden: a prospective observational cohort study. Br J Gen Pract. 2012;62(604):e773-e779.

50. Psaros C, Freeman M, Safren SA, Barsky M, Cohen LS. Discontinuation of antidepressants during attempts to conceive: a pilot trial of cognitive behavioral therapy for the prevention of recurrent depression. J Clin Psychopharmacol. 2014;34(4):455-460.

51. Psaros C, Freeman M, Safren S, Barsky M, Cohen L. Cognitivebehavioral therapy in women discontinuing antidepressant in anticipation of pregnancy. Neuropsychopharmacology. 2011;36:\$347.

52. Baldessarini RJ, Tondo L, Ghiani C, Lepri B. Illness risk following rapid versus gradual discontinuation of antidepressants. Am J Psychiatry. 2010;167(8):934-941.

53. Himei A, Okamura T. Discontinuation syndrome associated with paroxetine in depressed patients: a retrospective analysis of factors involved in the occurrence of the syndrome. CNS Drugs. 2006; 20(8):665-672.

54. Molenaar NM, Brouwer ME, Bockting CLH, et al. Stop or go? Preventive cognitive therapy with guided tapering of antidepressants during pregnancy: Study protocol of a pragmatic multicentre noninferiority randomized controlled trial. BMC Psychiatry. 2016;16:72.

55. Lambregtse-Van Den Berg M, Burger H, Bockting CL, Bonsel GJ, Duvekot JJ, Torij HW. Stop or go? Tapering antidepressants in pregnancy: A pragmatic multicenter RCT to investigate risk and benefits for mother and child. Arch Women Ment Health. 2015;18(2):403-404.
56. ClinicalTrials.gov. Tapering off antidepressants. https://clinicaltrials. gov/ct2/show/NCT02661828. Published Mar 17, 2017. Accessed Aug 2, 2018.

57. Black K, Shea C, Dursun S, Kutcher S. Selective serotonin reuptake inhibitor discontinuation syndrome: proposed diagnostic criteria. J Psychiatry Neurosci. 2000;25(3):255-261.

58. Mangin D, Dowson C, Mulder R, et al. The effectiveness of maintenance SSRI treatment in primary care depression to prevent recurrence: Multicentre double-blinded placebo controlled RCT. Presented at: North American Primary Care Research Group (NAPCRG) 43rd Annual Meeting; Oct 27, 2015; Cancun, Mexico. http://www.napcrg. org/Conferences/PastMeetingArchives/2015AnnualMeetingArchives/ SearchEducationalSessions? $m=6 \varepsilon s=14867$. Accessed Oct 8, 2018.

59. Buscemi N, Hartling L, Vandermeer B, Tjosvold L, Klassen TP. Single data extraction generated more errors than double data extraction in systematic reviews. J Clin Epidemiol. 2006;59(7):697-703.

60. Tint A, Haddad PM, Anderson IM. The effect of rate of antidepressant tapering on the incidence of discontinuation symptoms: a randomised study. J Psychopharmacol. 2008;22(3):330-332.

61. Montgomery SA, Kennedy SH, Burrows GD, Lejoyeux M, Hindmarch I. Absence of discontinuation symptoms with agomelatine and occurrence of discontinuation symptoms with paroxetine: a randomized, double-blind, placebo-controlled discontinuation study. Int Clin Psychopharmacol. 2004;19(5):271-280.

62. Paykel ES. Continuation and maintenance therapy in depression. $\mathrm{Br}$ Med Bull. 2001;57:145-159.

63. Geddes JR, Carney SM, Davies C, et al. Relapse prevention with antidepressant drug treatment in depressive disorders: a systematic review. Lancet. 2003;361(9358):653-661.

64. Reeve E, To J, Hendrix I, Shakib S, Roberts MS, Wiese MD. Patient barriers to and enablers of deprescribing: a systematic review. Drugs Aging. 2013;30(10):793-807. 